\title{
Approach to Geriatric Patients in Emergency Services
}

\author{
Acil Servislerde Geriatrik Hastalara Yaklaşım
}

\author{
Ayhan Sarıtaş ${ }^{1}$, Hayati Kandiş ${ }^{1}$, Davut Baltacı ${ }^{2}$ \\ 'Department of Emergency Medicine, Faculty of Medicine, Düzce University, Düzce, Turkey \\ 2Department of Family Medicine, Faculty of Medicine Düzce, University, Düzce, Turkey
}

\begin{abstract}
Geriatric patients represent a special group for emergency services. Geriatric patients usually apply to emergency services in more frequent and more severe situations than younger patients. Due to the rapid rise in the geriatric population, development of reinforcements in order to supply care for these patients becomes a more urgent issue for emergency services. In this paper, we aimed to present points which are important considerations in the management of geriatric group patients admitted to emergency room for emergency service workers, as a whole. It has been shown in many studies that there has been inadequate information and education for emergency physicians and nurses in identifying geriatric emergency situations. The majority of emergency physicians feel that inadequate time is spent on geriatric issues in residency, and that research in geriatric emergency medicine is inadequate. As a result, emergency physicians may play a key role in detecting important issues such as elder abuse, falling down, depression, alcoholism and malnutrition. We think that the creation of educational models and protocols for the recognition of geriatric emergency situations for emergency service workers will improve the quality of care given to geriatric patients in emergency services. (JAEM 2013; 12: 93-7)
\end{abstract}

Key words: Geriatric patients, emergency service, evaluation, disease

\section{Özet}

Geriatrik hastalar acil servisler için özel bir topluluğu temsil etmektedir. Yaşlı insanlar genellikle gençlere göre daha sık ve ağır durumda acil servislere başvurmaktadır. Geriatrik popülasyondaki hızlı artışa bağlı olarak acil servislerin bu hastaların bakımını karşılayacak destekleri geliştirmesi önem kazanmaktadır. Bu yazımızda acil servis çalışanlarına acil servislere başvuran geriatrik yaş grubundaki hastalara yaklaşımda önem arz eden ve dikkat edilmesi gereken noktaları bir bütün halinde sunmayı amaçladık. Acil hekimlerinin geriatrik hastalar ile ilgili düşünceleri; eğitimleri sırasında geriatrik sorunlar üzerine yetersiz zaman harcanması ve geriatri konusunda acil tıp araştırmalarının yetersiz olmasıdır. Sonuç olarak, yaşı istismarı, düşme, depresyon, alkolizm ve malnütrisyon gibi önemli konuların ortaya çıkarılmasında acil servis hekimleri anahtar rol oynayabilir. Acil servis çalışanları için geriatrik acil durumları tanımaya yönelik eğitim modellerinin ve protokollerin oluşturulmasının acil servislerde geriatrik hastalara bakımın kalitesini artıracağını düşünmekteyiz. (JAEM 2013; 12: 93-7)

Anahtar Kelimeler: Geriatrik hastalar, acil servis, değerlendirme, hastalık

Literatürde yaşlı hastaların acil servislere başvuru oranlarının \%13-14 olduğu bildirilmiştir $(2,7,8)$. Bir başka araştırmada bu oran \%23 olarak bulunmuştur (9). Strange ve ark. (3) ise 65-74 yaş arası nüfusun \%25'inin acil sağlık hizmetlerinden yararlandıklarını tespit etmişlerdir. Ambulans kullanımı da yaşla birlikte artmaktadır. Yetmiş beş yaş ve üstü kişilerin yaklaşık \%43'ü acil servise ambulans ile transfer edilmektedir (10). Acil sağlık hizmetlerinde ambulans kullanımı yıllık 11-139/1,000 arasında değişmektedir. Bu oran 65 yaş ve üzeri populasyonda en yüksek düzeye ulaşmaktadır (11).

Yaşı insanlar genellikle gençlere göre daha sık ve daha ağır durumda acil servislere başvurmaktadır. Geriatrik popülasyonundaki hızlı artışa bağlı olarak acil servislerin bu hastaların bakımını karşılayacak destekleri geliştirmesi önem kazanmaktadır $(12,13)$.

Address for Correspondence / Yazışma Adresi: Ayhan Sarıtaş, Department of Emergency Medicine, Faculty of Medicine, Düzce University, Düzce, Turkey Phone: +90 5319041000 e.mail: ayhansaritas@duzce.edu.tr

Received / Geliş Tarihi: 27.02.2011 Accepted/ Kabul Tarihi: 09.05.2012 Available Online Date / Çevrimiçi Yayın Tarihi: 27.02.2013

c) Copyright 2013 by Emergency Physicians Association of Turkey - Available online at www.akademikaciltip.com CTelif Hakkı 2013 Acil Tıp Uzmanları Derneği - Makale metnine www.akademikaciltip.com web sayfasından ulaşılabilir. doi:10.5152/jaem.2013.003 
Yaşlanma fizyolojisi; hastalıkların atipik prezantasyonlarına, farmakodinamik değişikliklere, fonksiyonel rezervde azalmaya, sosyal sorunlara yol açmaktadır. Neticede bu durumlar geriatrik hastaların acil serviste değerlendirilmesinde zorluklara sebep olmaktadır (14). Geriatrik hastaların değerlendirilmesi daha fazla zaman almakta ve daha fazla kaynak kullanımı gerektirmektedir. Ayrıca anksiyete ve acil servis çalışanları ile hasta ve/veya yakınları arasındaki iletişim problemleri de geriatrik hastaların acil servisteki değerlendirilmesini zorlaştıran faktörler olarak karşımıza çıkmaktadır. Acil hekimlerinin geriatrik hastalar ile ilgili genel düşünceleri; eğitimleri sırasında geriatrik sorunlar üzerine yetersiz zaman harcanması ve geriatri konusunda acil tıp araştırmalarının yetersiz olmasıdır (15). Yaşlılardaki atipik prezantasyonlara karşı acil servis ekibinin eğitimi geriatrik epidemi için acil servislerin hazırlanmasında anahtardır (16). Bu yazımızda acil servis çalışanlarına acil servislere başvuran geriatrik yaş grubundaki hastalara yaklaşımda önem arz eden ve dikkat edilmesi gereken noktaları bir bütün halinde sunmayı amaçladık.

\section{Acil Servise Başvuran Geriatrik Hastaların Genel Yapısı}

Kardiyopulmoner şikayetler en yaygın olanlarıdır. Göğüs ağrısı ve nefes darlığının her biri ana şikayetlerin \%11'ni oluşturur (15). Ross ve ark. (17) yaşlı hastalarda en sık acil servis başvuru nedeninin göğüs ağrısı (\%24) olduğunu bildirmişlerdir. Ünsal ve ark. (2) tarafından yapılan çalışmada, 112 acil sağlık hizmetlerini kullanan yaşlılarda, ilk beş hastalığın sırasıyla; hipertansiyon, akciğer hastalıkları, kardiyolojik hastalıklar, üst solunum yolu hastalıkları ve idrar yolu hastalıkları olduğu bulunmuştur. Victor ve ark. (18) \%24 ile kazaları birinci sırada gösterirken, Hu ve ark. (19) tarafından yapılan çalışmada ilk üç sırada serebrovasküler $(\% 6,6)$, kardiyovasküler $(\% 6,6)$ hastalıklar ve kanser $(\% 5,6)$ bulunmaktadır. Nur ve ark.'nın (20) Sivas'ta yaptıkları çalışmada ise, ilk üç sırada kardiyolojik ve nörolojik problemler ile solunum problemleri yer almaktadır. Karın ağrısı, baş dönmesi ve genel güçsüzlüğün her biri başvuruların yaklaşık \%3'ünde görülmektedir. Altmış beş yaş üstü acil servis hastalarının yoğun bakıma alınma, ambulans ile nakli, komorbid hastalıklara sahip olma ve test kaynaklarını yüksek oranda kullanma ihtimalleri çok daha fazladır (15). Yaşla birlikte birçok kronik hastalık insidansının artışı doğaldır. Ayrıca bu hastaların evde kendilerine bakmaları da zor olabilmektedir (21). Yapılan bir çalışmada, geriatrik yaş grubunun genç popülasyona göre 5.6 kat daha fazla hastaneye başvurduğu ve 5,5 kat daha fazla yoğun bakım ünitelerine kabul edildikleri gösterilmiştir (22).

\section{Genel Klinik Yaklaşım}

Geriatrik hastalara yaklaşım, diğer branşlardan farklı olarak, hem tıbbi hem de psikolojik, sosyoekonomik, çevresel ve ailesel açıdan da değerlendirilmelidir. Bu nedenlerledir ki geriatrik değerlendirme, birçok branşın birlikte çalışmasını gerektiren bir yaklaşım olarak karşımıza çıkmaktadır (1).

Geriatrik hastalardan anamnez alınırken bilişsel ve fiziksel problemler de göz önünde bulundurularak biraz daha fazla dikkatli ve titiz davranılmalı, mümkün olduğunca eksiksiz bir hikaye alınmaya çalışılmalıdır. Bilişsel problemler, geçmiş tıbbi sorunları hatırlamasını engelleyebilir. Aile bireyleri ve varsa bakıcısı ile görüşmek, hastaya ait geçmiş tıbbi dökümanlardan faydalanmak gerekebilir. Daha önce geçirilen inmeye bağlı afazi veya yaşlılarda sık gözlenen işitme problemleri iletişimde sorunlara neden olabilir (23).
Geriatrik hastalarda belirsiz yakınmalar sık olduğundan fizik muayenede buna dikkat edilmelidir. Genel halsizlik veya fonksiyonel zayıflık gibi bulanık şikayetler sepsis, subdural hematom veya miyokard infarktüsü gibi önemli hastalıklara bağlı olabilir. Sık görülen hastalıklar yaşı hastalarda atipik prezantasyon gösterebilir ve hekim bu populasyonda atipik prezantasyonları anlamaz ve şüphelenmez ise tanının atlanmasına neden olabilir (14). Acil hekimleri geriatrik hastalarda altta yatan ciddi probleme rağmen fizik muayenenin yanıltıcı bir şekilde normal olabileceğini de akıldan çıkarmamalıdır. Fizik muayeneyi etkileyebilen fizyolojik değişikliklerin yanı sıra, kullanılan ilaçlar da fizyolojik streslere verilen yanıtta değişikliklere yol açabilir (23).

Kognitif Bozukluk: Öncesinde kognitif sorunları olmayan acil servisteki geriatrik hastaların \%30-40'ı deliryum veya kognitif disfonksiyon kriterlerini taşımakta ve acil hekimleri tarafından bunlar sıklıkla tanınmamaktadır. Bu nedenle, yaşlı hastalar kognitif disfonksiyon açısından rutin olarak değerlendirilmelidir. Kognitif bozukluklar deliryum ve demanstır. Yaşlılardaki anormal kognitif durumlar hastadan alınan anamnezin güvenirliliğini ve tedavi planını etkileyebilmektedir. Acil servisten deliryumu olan hastaların taburcu edilmesi artmış mortaliteye yol açar. Acil servis hekimlerinin yaşlı hastaları değerlendirme zamanları sınırlı olduğundan ve kognitif disfonksiyonları değerlendirmek için kısa, sensitif testleri kullanmaları gerekmektedir. Acil servisteki geriatrik hastalarda kognitif değerlendirme için hangi testlerin kullanılacağı tartışmalıdır (15). En basit tarama aracı oryantasyon ve üç kelime hatırlama testidir. Eğer herhangi bir problem tespit edilmezse daha ileri testlerin yapılmasına gerek yoktur. Taramada sorun tespit edilirse ileri testler yapılmalıdır. Konfüzyon Değerlendirme Metodu skalası acil hekimleri için kullanışlı bir araçtır (Tablo 1) (24). Deliryum tanısı için ilk 2 kriterin olması ve 3. veya 4. kriterden birinin olması gerekir (24).

Deliryum, demans veya bilinçlilik düzeyinde azalma genellikle anamnez veya fizik muayene ile anlaşılabilir. Glasgow Koma Skalası azalmış bilinç düzeyini sınıflandırmada kullanılan diğer bir yöntemdir. Yaşı hastalarda akut mental durum değişiklikleri muhtemel organik nedenlere bağlı tıbbi acil durumun göstergesi olabileceğinden, etiyolojiyi tespit etmek için tanısal testleri gerekli kılar (25). Ayırıcı tanı pnömoni, ürosepsis, elektrolit imbalansı, ilaç reaksiyonları ve konjestif kalp yetmezliği gibi mental durumda azalmaya neden olan çok sayıda bozukluğu içerir (14).

Fonksiyonel Değerlendirme: Geriatrik hastaların acil serviste fonksiyonel açıdan değerlendirilmesi son derece önemlidir ve fonksiyonel rezervdeki azalma olasılığına karşı hazırlıklı olunmalıdır. Birçok hasta semptomlarda eşik seviyeye ulaşana kadar asemptomatik olabilir. Normal yaşlanma kardiyak, pulmoner, nörolojik, immünolojik, hepatik ve renal fonksiyonel rezervlerde azalmaya yol açmaktadır. Otuz yaşından sonra her yıl için yaklaşık \%1 oranında istirahatteki kardiyak output azalır $(14,15,26)$.

İlaç Kullanımı: Yaşı hastalarda olası uygunsuz ilaç kullanımı için net kriterler tanımlanmıştır. Bunlar uygunsuz ilaçlarla birlikte ilaç-hastalık ve ilaç-ilaç etkileşimleridir. İlaç veya ilaç etkileşimlerine bağlı yaygın komplikasyonlar deliryum, depresyon, fonksiyonel azalma, demansta kötüleşme, ortostatik hipotansiyon, güçsüzlük, dengesizlik ve inkontinansı içermektedir. Hastalara acil servis başvurusundan önce, acil serviste veya acil servisten taburcu edilirken uygun olmayan ilaç verilmiş olabilir $(15,27)$. Yaşı ı kişilerin yaklaşık 
Tablo 1. Konfüzyon değerlendirme metodu formu

\section{AKUT BAŞLANGIÇ VEYA DALGALI SEYIR}

Mental durumda akut bir değiş̧iklik kanıtı var mı? veya

Gün içinde anormal davranış dalgalanması oluyor mu?

Hayır

Evet

\section{DIKKAT BOZUKLUĞU}

Dikkate odaklanmada zorlanma var mı?

Hayır

Evet

\section{KARMAŞIK DÜŞÜNCE}

Hastanın düşüncesinde tutarsızlık veya karmaşıklık var mıydı?

Hayır

Evet

\section{BíLiNÇ DÜZEYINDE DEĞişiKLLiK}

Genel olarak hastanın bilinç düzeyini nasıl değerlendiriyorsun?

-Alert (normal)

-Dikkatli (hiperalert)

-Letarjik

Hayır

Evet

-Stupor

-Koma

Bu bölümde kontrole gerek herhangi bir durum var mı?

Deliryum tanısı için ilk 2 kriterin olması ve 3 . veya 4 . kriterden birinin olması gerekir.

olarak \%30'unda ilaç yan etkileri görülmekte ve bu oran gençlerdekinin 2 katıdır (26). Yaşla birlikte ilaçların vücuttaki dağılımı değişmekte, genişlemiş adipoz doku oranı benzodiyazepin, fenitoin, barbitürat ve fenotiyazin gibi ilaçların dağılım hacmini arttırmakta ve bunların etki sürelerinin uzamasına yol açmaktadır. İlaç klirensi primer olarak hepatik ve renal fonksiyonlara bağlıdır. Yaşla azalan renal fonksiyon digoksin ve aminoglikozid gibi ilaçları etkileyebilir. Yaşı ıişilerde, varfarin ve benzodiyazepinlere karşı duyarlılık artmıştır (27).

Komorbid Hastalıklar: Geriatrik hastalar sıklıkla kafa karıştırıcı komorbid hastalıklara sahip olacaktır ve acil hekimleri mevcut şikayetlerin komorbid hastalıkların bir alevlenmesine veya yeni bir hastalık sürecine bağlı olup olmadığını değerlendirmelidir. Özellikle çoklu ilaç ile tedavi edilen komorbid hastalıklar tedaviyi de etkileyebilmektedir.

Laboratuvar: Laboratuvar testlerini doğru yorumlayabilmek için yaşla değişen normal değerlerin bilinmesi gerekmektedir. Örneğin, sedimantasyon hızı, serum glukoz, kreatinin düzeyleri, arteryal oksijen basıncı gibi laboratuvar parametreleri fizyolojik yaşlanma ile değişiklikler gösterebilir (14).

Fonksiyonel Düşüş: Fonksiyonel düşüş kişinin bağımsız bir şekilde günlük yaşam aktivitelerini yerine getirebilme yeteneğindeki değişiklikleri ifade eder ve normal yaşlanma sürecinin bir parçası değildir. Banyo yapma, giyinme, tuvaletini yapma, transfer, kontinans ve beslenme gibi fonksiyonların değerlendirildiği Günlük Yaşam Aktiviteleri (GYA) standart ölçeği bu amaç için kullanılabilir (Tablo 2) $(28,29)$. Hastaya bu işlerin her birini tek başına veya birinin yardımı ile yapıp yapamadığı sorulur. Eğer hasta günlük yaşamdaki bu temel aktiviteleri yapamıyorsa bakıcıya gereksinimi vardır. GYA'da bozulma genellikle banyo yapma, giyinme, tuvalet, transfer ve beslenme şeklinde düzenli bir sırayı takip eder. Beslenme fonksiyonundaki bozulmanın diğerlerinden önce gerçekleşmesi gibi bu sıra görülmez ise organik hastalıklardan şüphelenilmelidir. Diğer bir skala, Enstrümental Günlük Yaşam Aktiviteleridir (EGYA); telefon kullanabilme, yürüme, alış veriş yapma, yemek hazırlama, ev işlerini yapma, el işlerini yapma, çamaşır yıkama ilaçları alabilme ve mali işleri takip edebilme gibi daha karmaşık yetenekleri değerlendirir (Tablo 2) $(28,29)$. Fonksiyonel düşüşte azalmanın ayırıcı tanısı miyokard infarktüsü, sepsis, subdural hematom ve ilaç yan etkileri gibi ciddi hastalıkları içermektedir. Acil serviste fonksiyonel değerlendirme hastaneye yatış, taburculuğu planlama ve gelecekteki sağlık bakımı gereksinimi konusunda yol gösterici olabilir (30).

\section{Spesifik Klinik Sendromlar}

\section{Karın Ağrısı}

Acil servise başvuran geriatrik hastaların \%3-6'sında karın ağrısı şikayeti mevcuttur. Yapılan çalışmalar göstermiştir ki; geriatrik hastaların yönetiminde acil servis hekimlerini en çok zorlayan ciddi semptomlardan birisidir. Ciddi hastalığın olmasına rağmen hastalarda sıklıkla klasik semptomlar, bulgular ve laboratuvar sonuçları yoktur (15). Örneğin akut apandisitli yaşlı hastalara sıklıkla geç tanı konulur ve perforasyon oranı yüksektir (31).

\section{Düşmeler}

Düşmeler yaşlı hastalarda hem yaygın hem de ciddidir. Altmış beş yaş üzeri travma başvurularının en yaygın nedenini oluştururlar (15). Düşmeler yaşlanmanın getirdiği normal bir süreç değildir. Düşme bir semptomdur ve acil hekimleri düşmenin hem nedenini hem de sonuçlarını araştırmak zorundadır (32). Düşme nedenleri akut veya kronik hastalıkları, kullanılan ilaçları ve çevresel faktörleri içermelidir. Acil servis hekimleri düşme nedenini sorgulamalı ve acil servis ortamında hangi ileri testlerin yapılması gerektiğini tespit etmelidirler (14).

\section{Enfeksiyon Hastalıkları}

Yaşla birlikte immün sistemde meydana gelen değiş̧ikliklerin yanı sıra birçok faktör yaşlılarda enfeksiyonlara yatkınlık artışından sorumludur (33). Geriatrik acil servis hastalarının yüksek mortalite ve morbiditesi olan en sık başvuru şikayeti ateştir. Ateşin olup olmaması yaşlı bireylerde özel önem taşımaktadır. Ciddi enfeksiyonu olan yaşıların \%30'unda ateş yanıtının baskılanmış olduğu tespit edilmiştir. Ateşin 
Tablo 2. Günlük Yaşam Aktiviteleri ve Enstrümental Günlük Yaşam Aktiviteleri Skalaları $(28,29)$

\begin{tabular}{|l|l|}
\hline $\begin{array}{l}\text { Günlük Yaşam Aktiviteleri } \\
\text { (GYA) Skalası (28) }\end{array}$ & $\begin{array}{l}\text { Enstrümental } \\
\text { Günlük Yaşam Aktiviteleri } \\
\text { (EGYA) Skalası (29) }\end{array}$ \\
\hline Banyo yapma & Telefon kullanabilme \\
\hline Giyinme & Yürüme \\
\hline Tuvaletini yapma & Alışveriş yapma \\
\hline Transfer & Yemek hazırlama \\
\hline Kontinans & Ev işlerini yapma \\
\hline Beslenme & El işlerini yapma \\
\hline \multirow{2}{*}{\begin{tabular}{l} 
Çamaşırı yıkama \\
\cline { 2 - 3 }
\end{tabular}} & İlaçları alabilme \\
\cline { 2 - 2 } & Mali işleri takip edebilme \\
\hline \multicolumn{2}{|l|}{$\begin{array}{l}\text { Hastaya bu işlerin her birini tek başına veya birinin yardımı ile yapıp yapamadığı } \\
\text { sorulur. Eğer hasta günlük yaşamdaki bu temel aktiviteleri yapamıorsa bakıııa } \\
\text { gereksinimi vardır. GYA'da bozulma genellikle banyo yapma, giyinme, tuvalet, } \\
\text { transfer ve beslenme şeklinde düzenli bir sırayı takip eder. Beslenme fonksiyo- } \\
\text { nundaki bozulmanın diğerlerinden önce gerçekleşmesi gibi bu sıra görülmez ise } \\
\text { organik hastalıklardan şüphelenilmelidir. }\end{array}$} \\
\hline
\end{tabular}

mevcut olduğu durumlarda, gençlere göre yaşlılarda ciddi enfeksiyon olma riski daha fazladır. Acil servise başvuran ateşli geriatrik hastaların \%89'unda enfeksiyon varlığı kanıtlanmıştır. En sık enfeksiyon kaynakları akciğerler, idrar yolları, abdomen ve deridir. Geriatrik hastalarda ateş ciddi olarak değerlendirilmeli ve hastanede yatırılarak tedavisi konusu öncelikli olarak düşünülmelidir $(15,23,34)$. Mellors ve ark. (35) yaptıkları çalışmada, lokalize semptom ve bulguları olmayan febril yetişkinlerde bakteriyemi ve gizli bakteriyal enfeksiyonun belirleyicileri olarak;

1) 50 yaşüstü

2) Diyabet

3) Beyaz küre sayısı $>15.000 / \mu \mathrm{l}$

4) Nötrofil sayısı $>1.500 / \mu \mathrm{l}$

5) Sedimantasyon $>30 \mathrm{~mm} / \mathrm{saat}$ tespit etmişlerdir.

Bu faktörlerden birinin veya ikisinin olduğu hastalarda, bakteriyemi veya fokal bakteriyel enfeksiyon riski 7-8 kat artmıştır.

İmmünizasyon acil servis pratiğinin rutin bir parçası haline gelmelidir (özellikle tetanoz immünizasyonu). Bu hastaların yaklaşık \%50'si tetanoza karşı koruyucu antikorlara sahip değildir. Yaşlı hastalar pnömokok ve influenza aşılanması için de acil serviste değerlendirilmelidir (15, 23, 34).

\section{Akut Koroner Sendrom}

Yaşlı hastalardaki göğüs ağrısı, acil hekimleri için endişe verici bir durum olarak tespit edilmiştir. Ayrıca gençlere göre daha fazla zaman harcanan ve değerlendirmek için daha fazla kaynak gerektiren bir şikayet olarak görülmektedir. Yaş artışı koroner arter hastalığı gelişimi için bir risk faktörüdür. Yaşlı hastalar, özelliklede 85 yaş üzeri, atipik akut koroner sendrom ile başvurabildiklerinden daha dikkatli olunmalıdır.

\section{Kardiyopulmoner Arrest}

Kardiyak ritmin varlığı ve arrest anına şahit olunması kardiyak arrest sonlanımını kestirmede yaştan daha önemli faktörlerdir. Arrest olduğu anı görmediğimiz ve asistolideki hastaların sonlanımı hangi yaşta olursa olsun daha kötüdür. Hangi hastalara resusitasyon uygulanacağını tespit etmek için ileri araştırmalara ihtiyaç olmasına rağmen bu kararı vermede tek başına yaş kullanılmamalıdır (15).

\section{Travma}

Travma yaşlılar arasında morbidite ve mortalitenin majör nedenlerinden biridir. Travma hastalarının \%20'sinden azı 65 yaş ve üstü kişiler olmasına rağmen travmaya bağlı ölümlerin \%28'i yaşlı hastalarda gözlenmektedir $(15,36)$. Yüksek mortalitesine ek olarak, geriatrik hastalarda travma fonksiyon kaybını ve başkalarından bağımsız yaşamayı ortadan kaldıran önemli morbiditeye neden olabilmektedir. Yaşlı travma hastalarında yapılan çalışmalarda, hastane içi mortalite \%15-45 arasında değişmektedir. Travma hastalarındaki mortalite travma şiddeti, bakımdaki dakiklik ve kaliteyi içeren değişik faktörlere bağlıdır. Azalmış fonksiyonel rezervlerinden dolayı yaşlılarda önemli komplikasyonlar ve uzamış hospitalizasyon ihtimali daha fazladır. Geriatrik popülasyonda travmanın en yaygın mekanizması düşmeler olup bunu motorlu araç ve yaya kazaları takip etmektedir (14). Kandiş ve ark. (37) yaptıkları çalışmada geriatrik poülasyonda travma nedeninin en sık trafik kazaları olduğunu tespit etmişlerdir. Multisistem travmalı yaşı hastaların tedavisi ile ilgilenen acil servis hekimleri için majör sorun hastadaki akut kötüleşmeye kadar, kan basıncı, nabız gibi standart fizyolojik indekslerin normal sınırlarda kalmasıdır. Ciddi travma geçiren tüm yaşlı hastalarda gizli şok tablosundan şüphe edilmelidir. Geriatrik travma hastalarının erken hemodinamik monitorizasyonu gizli şokun erken tespitini sağlayabilir ve sonuçta hayatta kalma şansını artırmaktadır (14).

\section{Sonuç}

Geriatrik yaş grubundaki hastalar kendi ev ortamı ve sosyal destek ağı şartları dikkate alınarak ele alınmalı, ayrıca bu grup hastalar acil servisten taburcu edilmeden önce hastaların aileleri ve arkadaşlarına ilave olarak sosyal destek sistemleri de durumları hakkında bilgilendirilmelidir. Son olarak, yaşlı istismarı, düşme, depresyon, alkolizm ve malnütrisyon gibi önemli konuların ortaya çıkarılmasında acil servis hekimleri anahtar rol oynayabilir. Acil servis çalışanları için geriatrik acil durumları tanımaya yönelik eğitim modellerinin ve protokollerin oluşturulmasının acil servislerde geriatrik hastalara bakımın kalitesini artıracağını düşünmekteyiz.

\section{Conflict of Interest / Çıkar Çatışması}

No conflict of interest was declared by the authors.

Yazarlar herhangi bir çıkar çatışması bildirmemişlerdir.

Peer-review: Externally peer-reviewed.

Hakem değerlendirmesi: Dış bağımsız.

\section{Author Contributions / Yazar Katkıları}

Concept / Fikir - A.S., H.K.; Design / Tasarım - A.S., D.B.; Supervision / Denetleme - A.S., H.K.; Funding / Kaynaklar - A.S.; Materials / Malzemeler - A.S.; Data Collection and/or Processing / Veri toplanması ve/veya işlemesi - A.S.; Analysis and/or Interpretation / Analiz ve/veya yorum - A.S., D.B.; Literature Review / Literatür taraması - A.S.; Writer / Yazıyı yazan - A.S.; Critical Review / Eleştirel Inceleme - A.D., H.K. 


\section{Kaynaklar}

1. http://www.turkgeriatrivakfi.org.tr/geriatri-hakkinda.html Erişim Tarihi 15.02.2012.

2. Ünsal A, Çevik AA, Metintaş S, Arslantaş $D$, İnan OÇ. Yaşıı hastaların acil servis başvuruları. Turk J Geriatrics 2003; 6: 83-8.

3. Strange GR, Chen EH. Use of emergency departments by elder patients: a five-year follow-up study. Acad Emerg Med 1998; 5: 1157-62. [CrossRef]

4. http://www.ceterisparibus.net/veritabani/1923_1990/nufus.htm Erişim Tarihi: 15.02.2012

5. http://tuikapp.tuik.gov.tr/adnksdagitapp/adnks.zul Erişim Tarihi 15.02 2012

6. Bilir N. Yaşılıık ve halk sağlığı. In: Gökçe-Kutsal Y (Ed): Yaşııık Gerçeği. Hacettepe Üniversitesi Hastaneleri Basımevi, Ankara, 2004, pp 11-29.

7. Ciccone A, Allegra JR, Cochrane DG, Cody RP, Roche LM. Age-related differences in diagnoses within the elderly population. Am J Emerg Med 1998; 16: 43-8. [CrossRef]

8. Durukan P, Çevik Y, Yıldız M. Acil Servise Karın Ağrısıyla Başvuran Yaşlı Hastaların Değerlendirilmesi. Turkish Journal of Geriatrics 2005; 8: 111-4.

9. Myers S. Patient care. Elderly emergency. Hosp Health Netw 2005; 79: $24-$ 6.

10. McCraig LF. National Hospital Ambulatory Medical Care Survey: 2000 Emergency Department Summary. Washington, DC, National Center for Health Statistics, Centers for Disease Control and Prevention, US Department of Health and Human Services, 2002.

11. Downing A, Wilson R. Older people's use of Accident and Emergency services. Age Ageing 2005; 34: 24-30. [CrossRef]

12. Singal $B M$, Hedges JR, Rousseau EW, Sanders AB, Berstein E, McNamara RM, et al. Geriatric patient emergency visits. Part l: Comparison of visits by geriatric and younger patients. Ann Emerg Med 1992; 21: 802-7. [CrossRef]

13. Ettinger WH, Casani JA, Coon PJ, Muller DC, Piazza-Appel K. Patterns of use of the emergency department by elderly patients. J Gerontol 1987; 42: 638-42. [CrossRef]

14. Sanders AB. The Elder Patient. Emergency Medicine: A Compehensive Study Guide. Ed: Tintinalli JE, Kelen GD, Stapczynski JS. Mc Graw Hill 6th Edition Sayfa 1896-900.

15. Wilber ST, Gerson LW. A research agenda for geriatric emergency medicine. Acad Emerg Med 2003; 10: 251-60. [CrossRef]

16. Foo CL, Chan KC, Goh HK, Seow E. Profiling acute presenting symptoms of geriatric patients attending an urban hospital emergency department. Ann Acad Med Singapore 2009; 38: 515-6.

17. Ross MA, Compton S, Richardson D, Jones R, Nittis T, Wilson A. The use and effectiveness of an emergency department observation unit for elderly patients. Ann Emerg Med 2003; 41: 668-77. [CrossRef]

18. Victor CR, Peacock JL, Chazot C, Walsh S, Holmes D. Who calls 999 and why? A survey of the emergency workload of the London Ambulance Service. J Accid Emerg Med 1999; 16: 174-8. [CrossRef]

19. Hu SC, Yen D, Yu YC, Kao WF, Wang LM. Elderly use of the ED in an Asian metropolis. Am J Emerg Med 1999; 17: 95-9. [CrossRef]

20. Nur N, Demir ÖF, Çetinkaya S, Tirek N. Yaşlılar tarafından kullanılan 112 Acil Sağlık Hizmetlerinin değerlendirilmesi. Türk Geriatri Dergisi 2008; 11: 7-11.
21. Baum SA, Rubenstein LZ. Old people in the emergency room: age-related differences in emergency department use and care. J Am Geriatr Soc 1987; 35: 398-404.

22. Strange GR, Chen EH, Sanders AB. Use of emergency departments by elderly patients: projections from a multicenter data base. Ann Emerg Med 1992; 21: 819-24. [CrossRef]

23. http://www.gata.edu.tr/dahilibilimler/ichastaliklari/egitim/aihk/47.pdf Erişim Tarihi 15.02.2012.

24. Inouye SK, van Dyck CH, Alessi CA, Balkin S, Siegal AP, Horwitz Rl. Clarifying confusion: the confusion assessment method. A new method for detection of delirium. Ann Intern Med 1990; 15: 941-8.

25. O'Keefe KP, Sanson TG. Elderly patients with altered mental status. Emerg Med Clin North Am 1998; 16: 701-15, [CrossRef]

26. Herrlinger C, Klotz U. Drug metabolism and drug interactions in the elderly. Best Pract Res Clin Gastroenterol 2001; 15: 897-918. [CrossRef]

27. Chin MH, Wang LC, Jin L, Mulliken R, Walter J, Hayley DC, et al. Appropriateness of medication selection for older persons in an urban academic emergency department. Acad Emerg Med 1999; 6: 1232-42. [CrossRef]

28. Katz S, Ford AB, Moskowitz RW, Jackson BA, Jaffe MW. Studies of illness in the aged. the index of adl: a standardized measure of biological and psychosocial function. JAMA 1963; 185: 914-9. [CrossRef]

29. Lawton MP, Brody EM. Assessment of older people: self-maintaining and instrumental activities of daily living. Gerontologist 1969; 9: 179-86. [CrossRef]

30. Lee V, Ross B, Tracy B. Functional assessment of older adults in an emergency department. Can J Occup Ther 2001; 68: 121-9.

31. Kraemer M, Franke C, Ohmann C, Yang Q; Acute Abdominal Pain Study Group. Acute appendicitis in late adulthood: incidence, presentation, and outcome. Results of a prospective multicenter acute abdominal pain study and a review of the literature. Langenbecks Arch Surg 2000; 385: 470-81. [CrossRef]

32. Weigand JV, Gerson LW. Preventive care in the emergency department: should emergency departments institute a falls prevention program for elder patients? A systematic review. Acad Emerg Med 2001; 8: 823-6. [CrossRef]

33. Gavazzi G, Krause KH. Ageing and infection. Lancet Infect Dis 2002; 2: 65966. [CrossRef]

34. Shortliffe LM, McCue JD. Urinary tract infection at the age extremes: pediatrics and geriatrics. Am J Med 2002; 113: 55-66. [CrossRef]

35. Mellors JW, Horwitz RI, Harvey MR, Horwitz SM. A simple index to identify occult bacterial infection in adults with acute unexplained fever. Arch Intern Med 1987; 147: 666-71. [CrossRef]

36. Mandavia D, Newton K. Geriatric trauma. Emerg Med Clin North Am 1998; 16: 257-74. [CrossRef]

37. Kandiş H, Karakuş A, Katırcı Y, Karapolat S, Kara IH. Geriatrik Yaş Grubu ve Adli Travmalar. Turkish Journal of Geriatrics 2011; 14: 193-8. 